\title{
An Analysis of Quality of Work Life (QWL) and Career- Related Variables
}

\author{
${ }^{1}$ Raduan Che Rose, ${ }^{2}$ LooSee Beh, ${ }^{3}$ Jegak Uli and ${ }^{3}$ Khairuddin Idris \\ ${ }^{1}$ Graduate School of Management, University Putra Malaysia, Malaysia \\ ${ }^{2}$ Faculty of Economics and Administration, Department of Administrative Studies and Politics \\ University of Malaya, Malaysia \\ ${ }^{3}$ Faculty of Educational Studies, Department of Professional Development and Continuing Education \\ University Putra Malaysia, Malaysia
}

\begin{abstract}
The aim of this study was to determine the level and relationship between qualities of work life (QWL) with career-related variables. The sample consists of 475 executives from the electrical and electronics industry in the free trade zones in Malaysia for both the multinational corporations (MNCs) and the small-medium industries (SMIs). The selection of respondents using stratified random sampling technique involves a complete list of industrial firms registered with Malaysian Industrial Development Authority (MIDA). Construct validity and discriminant validity were conducted on the instruments. Three exogenous variables were studied. The result indicates that the three exogenous variables are significant: career satisfaction, career achievement and career balance with $63 \%$ of the variance in QWL. The respondents appeared to be satisfied in respect to the level of QWL (49.5\%), career achievement $(70.3 \%)$, career satisfaction $(63.8 \%)$, but less so for career balance (36.6\%). These findings contribute to an understanding of ways by top management in attempts to attain a career fit between the needs of the employees and the needs of the organization. The role QWL plays in organizations is an understudied issue. The present study opens an avenue for more studies in this direction.
\end{abstract}

Key words: Quality of work life (QWL), career-related variables

\section{INTRODUCTION}

Although research has uncovered important predictors of Quality of Work Life (QWL), yet it has been absent present and has not been fully explored. To date, much of the empirical research on QWL has implicitly, if not explicitly, adopted a contemporary view of job satisfaction, stress, labor relations and a broad based view of occupation. Past scholars have offered a variety of definitions and suggestions of what constitutes QWL. For instance, QWL is a philosophy, a set of principles, which holds that people are the most important resource in the organization as they are trustworthy, responsible and capable of making valuable contribution and they should be treated with dignity and respect ${ }^{[1]}$. The elements that are relevant to an individual's quality of work life include the task, the physical work environment, social environment within the organization, administrative system and relationship between life on and off the job ${ }^{[2]}$. QWL consists of opportunities for active involvement in group working arrangements or problem solving that are of mutual benefit to employees or employers, based on labormanagement cooperation. People also conceive of QWL as a set of methods, such as autonomous work groups, job enrichment and high-involvement aimed at boosting the satisfaction and productivity of workers ${ }^{[3]}$.
It requires employee commitment to the organization and an environment in which this commitment can flourish ${ }^{[4]}$. Thus, QWL is a comprehensive construct that includes an individual's job related well-being and the extent to which work experiences are rewarding, fulfilling and devoid of stress and other negative personal consequences ${ }^{[5]}$.

Accordingly, the rising number of two-income households is heightening the concern for employees' quality of work life. Given that female participation at work is increasing, it is apparent that males and females independently will need to take care of both work and home. Therefore, quality of work experience rather than work per se became the focus of attention ${ }^{[6]}$ and workplace wellness is crucial in promoting healthier working environments ${ }^{[7]}$.

In fact, Malaysia's industrial growth has created a high demand for labor in the manufacturing sector. Malaysia's electrical and electronics (E\&E) industry is the largest contributor to the country's manufacturing output, employment and exports. The E\&E industry continues to be Malaysia's largest export earner at $65.5 \%$ during the first six months of the year $2003^{[8]}$. Hence, the E\&E industry creates the largest number of job opportunities, totaling 20,493 in 2002 in the manufacturing projects out of the total of $68,575^{[9]}$. Due to the importance of this industry, it is a necessity to

Corresponding Author: $\quad$ LooSee Beh, Faculty of Economics and Administration, Department of Administrative Studies and Politics, University of Malaya, Malaysia 
evaluate the working environment of the executives in this sector that require medium to high skills. This is consistent with the finding that competition in world markets for products in electronics has increased considerably over the past few years. If this trend continues, this sector will become even more competitive in the years to come ${ }^{[10]}$.

In summary, the limitations of individual job satisfaction had been pointed out in the literature for assessing the QWL and there had been no attempt in the past to measure QWL in terms of career aspects and organizational climate. This study is an attempt in such endeavor to further develop theoretical underpinnings to the available literature on QWL.

\section{Proposed model}

Career and QWL: The term QWL was introduced in the late 1960s as a way of focusing on the effects of employment on health and general well-being and ways to enhance the quality of a person's on the job experience. QWL is much broader and more diverse than organizational development, in ensuring adequate and fair compensation, safe and healthy working conditions, opportunities for personal growth and development, satisfaction of social needs at work, protection of employee rights, compatibility between work and non-work responsibilities and the social relevance of work-life ${ }^{[4,11]}$.

Meaningful and satisfying work is said to include: (1) an opportunity to exercise one's talents and capacities, to face challenges and situations that require independent initiative and self-direction (and which therefore is not boring and repetitive work); (2) in an activity thought to be of worth by the individual involved; (3) in which one understands the role one's activity plays in the achievement of some overall goal; and (4) take pride in what one is doing and in doing it well. This issue of meaningful and satisfying work is often merged with discussions of job satisfaction, however, the author believed this favorable estimate to QWL instead.

There are three distinctive elements of QWL related interventions: (1) a concern about the effect of work on people as well as organizational effectiveness, (2) the idea of worker participation in organizational problem solving and decision making and (3) the creation of reward structures in the workplace which consider innovative ways of rewarding employee input into the work process such as gainsharing, etc ${ }^{[12]}$. In the 1980s, emphasis was increasingly placed on employeecentered productivity programs. In the mid 1990s till today faced with challenges of downsizing and corporate restructuring, QWL is reemerging where employees are seeking out more meaning where rising educational levels and occupational aspirations in today's slow economic growth and reduced opportunities for advancement, naturally, there are rising concerns for QWL and for career and personal life planning.

Most people want to improve their performance on the job, to receive constructive suggestions regarding areas they need to work on and to be commended on their job well done. Thus, employees during their career will like to experience growth and development, a sense of where one is going in one's work life. QWL encompasses the career development practices used within the organization such as placing clear expectations on employees on their expectations and succession plans. QWL is linked to career development and career is evolving from such interaction of individuals within the organizations.

Career arises from the interaction of individuals with organizations and society. Career is not primarily a theoretical construct but is used in meaningful ways, given meaning and it creates meaning and also experience. Careers are typically defined as a 'sequence of work roles ${ }^{[13]}$ or a sequence of a person's work experiences over time ${ }^{[14]}$.

\section{Literature review}

QWL: Indeed, it is difficult to best conceptualize the quality of work life elements ${ }^{[15]}$. Walton ${ }^{[4]}$ proposed eight major conceptual categories relating to QWL as (1) adequate and fair compensation, (2) safe and healthy working conditions, (3) immediate opportunity to use and develop human capacities, (4) opportunity for continued growth and security, (5) social integration in the work organization, (6) constitutionalism in the work organization, (7) work and total life space and (8) social relevance of work life. Several published works have addressed the constructs that make up the QWL domain and key elements of QWL programs ${ }^{[1-5,16]}$. Others such as Pelsma et al. ${ }^{[17]}$ and Hart ${ }^{[18]}$ found that psychological distress and morale contributed equally to teachers' QWL. They determined that in the work climate of an occupation, QWL can be assessed by combining the amount and the degree of stress and the degree of satisfaction experienced by the individual within his/her occupational role. Winter et al. ${ }^{[19]}$ viewed QWL for academicians as an attitudinal response to the prevailing work environment and posited five work environment domains that include role stress, job characteristics, supervisory, structural and sectoral characteristics to directly and indirectly shape academicians' experiences, attitudes and behavior.

Career satisfaction: Career satisfaction is defined as the satisfaction individuals derive from intrinsic and extrinsic aspects of their careers, including pay, advancement and developmental opportunities ${ }^{[20]}$. This is in contrast to job satisfaction defined as pleasurable or positive emotional state resulting from an appraisal of one's job or job experiences. Korman et al. ${ }^{[21]}$ developed a construct called materialistic ethic. 
It states that a career is more satisfying if it is higher in prestige, income and power in comparison to other positions. In reviewing the literature, it is found that managers tend to evaluate their careers based on these factors.

It can be said that career satisfaction is largely a matter of an individual comparing his/her career and life expectations with those being offered. In shaping such career expectations, there are economic considerations (e.g. compensation and retirement benefits) and occupational and family considerations (professional satisfaction, job satisfaction, advancement opportunities, relocation, etc.). Some research indicates that a happy family life correlates with high levels of job satisfaction and objective career success ${ }^{[22]}$. Rapoport and Rapoport ${ }^{[23]}$ supported this by showing that the family's morale support and the diversion that it entails make it an important factor affecting QWL. Based on Judge et al. ${ }^{[24]}$, career success/achievement is defined as the positive psychological outcomes or achievements one has accumulated as a result of experiences over the span of working life which consists of objective career success (job title, salary or promotion) and subjective career success (one's own appraisal of career attainment). Research also suggests that job tenure and total time in one's occupation are positively related to career success/achievement besides the number of hours worked per week and salary and ascendancy $^{[25]}$. A positive relationship between ambition and career success has been found in several studies of managers and executives ${ }^{[26,27]}$. Herriot ${ }^{[27]}$ recognizes that sometimes there is a conflict between personal life and work and differences in perceptions of "success" in life. The perception of career includes beliefs and values, expectations and aspirations.

According to Gattiker and Larwood ${ }^{[28]}$, career satisfaction refers to the overall affective orientation of the individual toward his or her career. It is only one facet of a person's job satisfaction, since a person satisfied with his or her career may not be satisfied with another facet, e.g. working conditions of one's job.

Career satisfaction has been linked to several important organizational outcomes such as organizational commitment ${ }^{[29,30]}$, intentions to turnover $^{[30]}$ and support for organizational change ${ }^{[31]}$. Satisfaction with career is found to be negatively related to intention to leave and this relationship is as strong as perception of the labour market, the most reliable predictor in the research literature on turnover ${ }^{[32]}$.

One of the interesting findings from pay satisfaction research is the modest strength of the relationship between how much people are actually paid and their satisfaction with pay. Although this relationship is consistently positive and statistically significant, actual salary generally accounts for less than $25 \%$ of the variance in pay satisfaction. Those with the highest pay are not always the most satisfied with their pay ${ }^{[33]}$.

Drawing from above, it is hypothesized that:

Hypothesis 1: Career satisfaction is positively related to QWL.

Career achievement and QWL: Many career models propose that individuals may view their career differently depending on which age-related career stage they are in Judge et al. ${ }^{[34]}$ and Veiga ${ }^{[35]}$. In particular, researchers have observed that in early stages of their careers, individuals are often willing to sacrifice their personal lives in the interests of their career progression. Research also suggests that career tenure and total tenure in one's occupation are positively related to career achievement ${ }^{[24]}$. Thus, having occupational tenure and international experience will positively predict career success. The level of accomplishment in their job and career should affect career achievement. Considerable research also supports the relationship between the number of hours worked per week and salary and ascendancy ${ }^{[24,25]}$ meaning that the desire to spend time at work predicts career achievement. Cox and Cooper ${ }^{[25]}$ in trying to discover the motivation behind successful executives' long work hours, found that these executives enjoyed working long hours. It was found that ambition or the desire to get ahead was one of the best predictors of advancement in their study of American Telegraphic \& Transfer (AT \& T) managers. A positive relationship between ambition and career achievement has been found in several other studies of managers and executives ${ }^{[25,26]}$. Drawing from the above, it is predicted that:

Hypothesis 2: The total career tenure and tenure with the current employer are positively related to QWL.

Hypothesis 3: Career achievement is positively related to QWL.

Career balance: Past studies indicate that family roles reflect needs, opportunities and constraints have influence on individuals' reactions to work. After all, two important focal points of adult life are family and work. The role expectations of these two domains are not always compatible thus creating conflicts ${ }^{[36]}$. These conflicts are related to outcomes such as job dissatisfaction, job burnout and turnover ${ }^{[37-39]}$, as well as to outcomes related to psychological distress e.g. depression and life and marital dissatisfaction ${ }^{[40-42]}$. Work-family conflict studies have contributed to a better understanding of role conflict and its impact on mental health and the quality of work life ${ }^{[43]}$.

The amount of time and energy devoted to work needs to balance the time and energy devoted to life, 
thus, career balance. As Cascio ${ }^{[44]}$ mentioned, the focus is on enriching the overall quality of life and reframing the focus from work to life and from balance to quality. In respect to career balance, Herriot ${ }^{[27]}$ recognizes that sometimes there is a conflict between personal life and work and differences in perceptions of success in life. Two important focal points of adult life are family and work. Nevertheless, the role expectations of these two domains are not always compatible, creating conflicts between work and family life ${ }^{[36]}$. Due to the conflicting roles between work and family and commitment, it is hypothesized that a higher conflict in the work role will result in the lower quality of family life, meaning that a higher conflict will result in the lower level of QWL, in other words, having a balance between work and family will result in the higher level of QWL, thus resulting in:

Hypothesis 4: Career balance is positively related to QWL.

With justification from the literature, it is reasonable to suggest that aspects of career development with reference to career satisfaction and career achievement are factors that are likely to have impact on QWL. Likewise, career balance with the rising indication of conflict between work and family life is also proposed as another factor determining QWL.

Research method: This study employed the survey method that allow for broad coverage, flexibility and convenience with inputs on related populations or events. Collection of data was self-administered to determine the level of QWL. Participation was granted through prior appointments and consent via phone calls from the organization. Each organization was visited at least twice by the researcher to establish rapport and reinforce contacts with the top management and related personnel to ensure smooth implementation of the questionnaire distribution and collection. A third visit was made to ensure a degree of interest and commitment on the part of the respondents to collect the questionnaires if data collection was not possible the second round, in addition to follow-up appeal via phone calls. Questionnaires that are not received after the fourth week were classified as non-respondents.

Since this research is not a replication of any previous studies, the questionnaire was developed through literature review and a mix and match approach was undertaken to modify the sentence or complete withdrawal wherever necessary to suit the local context. While academics assisted in assessing face validity, the managerial professionals in a multinational corporation verified content validity. The final questionnaire was pre-tested on 19 managers. The coefficient values were all above 0.8 , thus meeting Nunnally's ${ }^{[45]}$ recommendation of $>0.7$ as the acceptable reliability level. The overall alpha value was .8768 . The final questionnaire had a total of 64 items measuring four constructs (three independent and one dependent).

A ten-point scale with 1 being "strongly disagree" and being 10 "strongly agree" was used. The type of statistical analysis required for this study (i.e. multiple regression analysis) dictated the use of an interval scale, one which guaranteed that the distances between adjacent numbers were the same and had no true zero $^{[46]}$. Therefore, the anchors of scale points were limited to the extremes without having any between. As advised by Allen and Rao ${ }^{[47]}$, calculating means and standard deviations are "highly suspect" if ordinal-level scales are used. Further, for a narrow scale there are low levels of intercorrelation and limited variance ${ }^{[47,48]}$.

A stratified random sampling procedure was employed. The selection of respondents using this technique involves a complete list of industrial firms, multinationals (MNCs) and small-medium industries (SMIs) from the Malaysian Industrial Development Authority (MIDA) that serves as an international investment manufacturing arm, according to different areas and the number of managers respectively in the areas. A total of 475 respondents as a good representative of the target population of approximately 2,622 managers and executives were reached over a two and a half month period in the year 2004. The sample was from the hub of industrial free trade zones in the state of Selangor near Kuala Lumpur, in the prime areas of the location of the $\mathrm{E} \& \mathrm{E}$ industry where many of the MNCs as well as the SMIs are situated and is accessible.

\section{RESULTS}

The quantitative data collected was subjected to various statistical analyses. Stepwise regression, a method by which each predictor variable is selected for inclusion in the model based on the significance of $t$ statistics in a step-by-step selection, was chosen based on the premise that multicollinearity, which is a common problem in multiple regression, could be somewhat circumvented $^{[48]}$. In this study, a default $\alpha$ of 0.05 was used to determine the level of significance. Table 3 contains summary statistics, Cronbach's alphas and zero-order correlation matrix for the variables under study.

In total, the final number collected was 480 of which 5 were not used as their designation positions were not from the sampling requirements as they were non-executives. Hence, the final usable sample was reduced to 475 which had a returned rate of $95 \%$. By and large, it was felt that the samples were representative of the populations for the respective areas studied.

Of the respondents, 67.2 per cent were male and 32.8 per cent were female. The majority of the respondents were aged 30-39 years (49.7\%), 
Am. J. Applied Sci., 3 (12): 2151-2159, 2006

Table 1: Descriptive statistics for the sample

\begin{tabular}{lcccc}
\hline Descriptive Statistics & $\mathrm{Y}_{1}(\mathrm{QWL})$ & $\mathrm{X}_{1}$ Career Satisfaction & $\mathrm{X}_{2}$ Career Achievement & $\mathrm{X}_{3}$ Career Balance \\
\hline Mean & 6.39 & 6.39 & 6.68 & 5.68 \\
Median & 6.50 & 6.40 & 6.85 & 5.60 \\
Standard Deviation & 1.46 & 1.11 & 1.41 & 1.15 \\
Minimum & 2.30 & 2.70 & 2.08 & 1.93 \\
Maximum & 10.00 & 10.00 & 10.00 & 10.00 \\
Interquartile Range (IQR) & 2.00 & 1.50 & 1.77 & 1.53 \\
Skewness & -.209 & -.242 & -.570 & .112 \\
Percentile & 5.40 & & 5.85 & 4.93 \\
$25^{\text {th }}$ & 6.50 & 5.70 & 6.85 & 5.60 \\
$50^{\text {th }}$ & 7.40 & 6.40 & 7.62 & 6.47 \\
$75^{\text {th }}$ & 8.24 & 7.20 & 8.39 & 7.13 \\
$90^{\text {th }}$ & & 7.80 & & \\
\hline
\end{tabular}

Table 2: Pearson correlation coefficient

Variables

\begin{tabular}{lccc}
\hline Descriptive Statistics & Total career tenure & Tenure with current employer & Y \\
\hline Total career tenure & 1 & $.699^{* *}$ & $.120^{* * *}$ \\
Tenure with current employer & $.699^{* *}$ & .000 & .009 \\
& .000 & 1 & $.135^{* *}$ \\
\hline
\end{tabular}

${ }^{\mathrm{a}}$ Pearson Correlation, ${ }^{\mathrm{b}}$ Sig. (2-tailed), $\mathrm{n}=475$.

${ }^{* *}$ Correlation is significant at the 0.01 level (2-tailed)

Table 3: Descriptive Statistics, zero-order correlations and Cronbach's alpha of QWL and the predictor variables

\begin{tabular}{|c|c|c|c|c|c|c|c|}
\hline \multicolumn{2}{|c|}{ Variables } & \multirow{2}{*}{$\begin{array}{l}X \\
6.3882\end{array}$} & \multirow{2}{*}{$\begin{array}{l}\mathrm{s} \\
1.45784\end{array}$} & \multirow{2}{*}{$\begin{array}{l}\mathrm{Y} \\
0.84\end{array}$} & \multirow[t]{2}{*}{$X_{1}$} & \multirow[t]{2}{*}{$\mathrm{X}_{2}$} & \multirow[t]{2}{*}{$\mathrm{X}_{3}$} \\
\hline $\mathrm{Y}$ & QWL (10) & & & & & & \\
\hline $\mathrm{X}_{1}$ & Career satisfaction (10) & 6.3905 & 1.11479 & 0.60 & 0.87 & & \\
\hline $\mathrm{X}_{2}$ & Career achievement (13) & 6.6766 & 1.41228 & 0.71 & 0.72 & 0.82 & \\
\hline \multirow{4}{*}{\multicolumn{8}{|c|}{$\begin{array}{l}\text { Notes: Figures in parentheses are the number of items measuring each construct; figures in italics are Cronbach's alpha; zero-order coefficien } \\
<0.01 \text {. }\end{array}$}} \\
\hline & & & & & & & \\
\hline & & & & & & & \\
\hline \multicolumn{2}{|c|}{ QWL dimension } & lized Coefficients) & Std. Error & Beta (Standardized Coefficients) & & & \\
\hline \multicolumn{2}{|c|}{ Constant } & 175 & 0.275 & & & 4.278 & 0.0001 \\
\hline \multicolumn{2}{|c|}{ Career achievement $\left(\mathrm{X}_{2}\right)$} & 365 & 0.047 & \multicolumn{2}{|c|}{0.354} & 7.748 & 0.0001 \\
\hline \multicolumn{2}{|c|}{ Career balance $\left(\mathrm{X}_{3}\right)$} & 125 & 0.038 & \multicolumn{2}{|c|}{0.098} & 3.269 & 0.001 \\
\hline \multicolumn{2}{|c|}{ Career satisfaction $\left(\mathrm{X}_{1}\right)$} & 178 & 0.055 & \multicolumn{2}{|c|}{0.136} & 3.209 & 0.001 \\
\hline
\end{tabular}

Notes: $\mathrm{R}=0.791 ; \mathrm{R}^{2}=0.626 ;$ Adj. $\mathrm{R}^{2}=0.623$, Durbin-Watson $=1.999$.

followed by $40-49$ years (23.8\%), 24-30 years $(21.9 \%)$ and $>50$ years $(4.6 \%)$. The average age is 36.33 years $(\underline{\mathrm{SD}}=6.905)$ with the youngest 24 years and oldest 58 years. The majority was married $(77.5 \%)$, followed by singles $(20.4 \%)$, divorced/separated $(0.8 \%)$ and living with partner $(0.8 \%)$. The majority has bachelors degree $(49.7 \%)$, diploma $(30.1 \%)$, professional degree $(10.9 \%)$, masters degree $(8.2 \%)$ and certificate level (1.1\%). $44.2 \%$ of the respondents had less than 10 years of total tenure employment, followed by $43.6 \%$ (11-20 years), $11.2 \%$ (21-30 years) and $1.1 \%$ (> 30 years). They had worked an average of 12.5 years $(\underline{S D}=6.9639)$ in their career with a minimum of 3 months and a maximum of 37 years with an average tenure of 9.2 years $(\underline{\mathrm{SD}}=6.116)$ with a minimum of 3 months and a maximum of 32 years with the current employer.

Level of QWL: Based on the ten-point scale used, the minimum QWL rating was 2.30 and a maximum of 10.00 and this gives a range of 7.70 as shown on
Table 1. The median QWL rating value was 6.40 with a standard deviation of 1.46. The mean QWL rating was 6.39 implying that overall the level of QWL is good. The $25^{\text {th }}$ percentile of the QWL is 5.40 and the $75^{\text {th }}$ percentile is 7.40 and thus the interquartile range (IQR) is 2.00. The values obtained for the $25^{\text {th }}$ and $75^{\text {th }}$ percentile suggest that $50 \%$ of the respondents have a QWL rating between 5.40 and 7.40. The $90^{\text {th }}$ percentile of the QWL is 8.24, which mean that $90 \%$ of the respondents have a QWL reading of 8.24 or less. In other words, only $10 \%$ of respondents obtained a QWL reading of above 8.24 . In accordance with the ratings of below 4 is low, 4-6 is moderate, 7-8 is good and above 8 is excellent as the indication of satisfaction, the executives appeared to have been rather satisfied with their level of QWL. The executives who felt that their level of QWL is good (49.5\%), moderate (30.7\%), excellent $(13.1 \%)$ and low $(6.1 \%)$. The findings in Table 3 indicate that the mean ratings for the independent variables in descending order of high to low are career achievement $(\underline{\mathrm{M}}=6.6766, \underline{\mathrm{SD}}=1.4123)$, 
career satisfaction $(\underline{\mathrm{M}}=6.3905, \underline{\mathrm{SD}}=1.1148)$ and career balance $(\underline{\mathrm{M}}=5.6749, \underline{\mathrm{SD}}=1.1499)$.

As depicted in Table 2 and 3, QWL is positively related to career satisfaction $(\mathrm{r}=.60, \mathrm{p}=0.001)$, career achievement $(\mathrm{r}=.71, \mathrm{p}=.0001)$, career balance $(\mathrm{r}=$ $.14, \mathrm{p}=.001)$.

Hence hypotheses 1, 2, 3 and 4 are supported.

Predictors of QWL: To find out the predictors of QWL, a stepwise regression method was used. Based on the stepwise method used, only four predictor variables were found to be of significance in explaining QWL. The three predictor variables are career satisfaction $\left(\mathrm{X}_{1}\right)$, career achievement $\left(\mathrm{X}_{2}\right)$ and career balance $\left(\mathrm{X}_{3}\right)$.

As depicted in the coefficients table (Table 4), the estimates of the model coefficients for $\beta_{0}$ is $1.175, \beta_{1}$ is $0.178, \beta_{2}$ is $0.365, \beta_{3}$ is 0.125 and $\beta_{4}$ is 0.383 . Therefore, the estimated model is as below:

$\mathrm{Y}(\mathrm{QWL})=1.175+0.178\left(\mathrm{X}_{1}\right)+0.365\left(\mathrm{X}_{2}\right)+0.125$ $\left(\mathrm{X}_{3}\right)+E$

Where:

$\mathrm{X}_{1}=$ career satisfaction,

$\mathrm{X}_{2}=$ career achievement,

$\mathrm{X}_{3}=$ career balance.

The R-squared of 0.626 implies that the four predictor variables explain about $62.6 \%$ of the variance in the QWL. This is quite a respectable result. The ANOVA table revealed that the F-statistics (157.126) is very large and the corresponding p-value is highly significant (0.0001) or lower than the alpha value of 0.05. This indicates that the slope of the estimated linear regression model line is not equal to zero confirming that there is linear relationship between QWL and the three predictor variables.

As depicted in Table 4, the largest beta coefficient is 0.429 which is for organizational climate. This means that this variable makes the strongest unique contribution to explaining the dependent variable (QWL), when the variance explained by all other predictor variables in the model is controlled for. The Beta value for career achievement is the second highest (0.354), followed by career satisfaction in the third place (0.136). The Beta value for career balance is the smallest (0.098) indicating that it made the least contribution. Based on the collinearity diagnostic table obtained, none of the model dimensions has condition index above the threshold value of 30.0, none of tolerance value smaller than 0.10 and VIF statistics are less than 10.0. This indicated that there is no serious multicollinearity problem among the predictor variables of the model. The normal P-P plot of regression standardized residuals revealed all observed values fall roughly along the straight line indicating that the residuals are from a normally distributed. The scatterplot (standardized predicted values against observed values) indicate the relationship between the dependent variables and the predictors is linear and the residuals variances are equal or constant. Since there is no multicollinearity problem between the predictors included in the model and the assumptions of normality, equality of variance and linearity are all met, hence, it is reasonable to conclude that the estimated multiple regression model is valid and quite respectable.

\section{DISCUSSION}

Without doubt, given the data, the most important predictor of QWL is organizational climate, followed by career achievement, career satisfaction and career balance. This finding is consistent with what was found by other researchers ${ }^{[49-51]}$, i.e. organizations and individuals are interdependent and that organizational climate characterized by warmth, friendliness and fair rewards are conducive for high-performance work orientation, useful in promoting motivation and satisfaction in their work and sense of accomplishment which will ultimately affect their performance. Similarly, employees of organizations characterized by supportive managerial relationships, group decision making and organization-wide goals experienced less burnout $^{[52]}$. Sommer et al. ${ }^{[51]}$ also found that Korean employees perceived a more negative organizational climate is seen as detrimental to positive feelings about the workplace (e.g. support, recognition, rewards and responsibility).Also, the respondents who worked in MNCs were reported to have a slightly higher level of QWL as compared to those in SMIs. The higher the income obtained by the respondents, the higher the level of QWL.

However, the respondents did not express the level of satisfaction with their career balance. This is in line with the literature standpoint and expressed in the conflict between work and family life. The results show that the respondents are satisfied with their achievement $(63.8 \%)$ in their career progress but not in terms of career balance $(36.6 \%)$. Participation in the work (family) role is made more difficult by virtue of participation in the family (work) role ${ }^{[40]}$. Executives who value their career quite highly will find that it affects the amount of time they can devote to the family $^{[28]}$. Rapoport and Rapoport ${ }^{[23]}$ supported this by showing that the family's morale support and the diversion that it entails make it an important factor affecting QWL. There is significant difference of QWL between married and singles $(\mathrm{F}=1.644$, $\mathrm{df}=463, \mathrm{p}=$ 0.02). Those who are married and have children have a higher level of QWL as compared to the singles. Past researchers have observed that in early stages of their careers, individuals are often willing to sacrifice their personal lives in the interests of their career progression. However, as individuals advance in age to the maturity stage of their career, they have been found to place a greater emphasis on a balance between their work and family lives that individuals place on their 
family role as they age. Prior research has found that being married leads individuals to give their personal lives priority over their work lives. Similarly, being a parent increases the importance that individuals place on their family role. Some research indicates that a happy family life correlates with high levels of job satisfaction and objective career achievement ${ }^{[22]}$. This is supported in this sample of study.

In this study, the E \& E industry comprises mostly Japanese companies where the workers tend to have higher work centrality and place a greater emphasis on job security and stability even though they are Malaysians. This finding is in accordance with Lundberg and Peterson ${ }^{[53]}$ and England and Misumi ${ }^{[54]}$. This suggests that Japanese have instituted similar cultures in Malaysia and even perhaps that our Malaysian culture, may be more attracted to traditional careers with an average tenure of 9.2 years with the current employer and in contrast to the boundaryless career concept that capture the working lives of Americans more accurately.

Implications: From a practical standpoint, our findings suggest that organizational climate does matter and it matters most among the predictors. In this respect, organizations need to pay great attention to their practices and provide conducive environment to their employees in gaining recognition to their career achievement in their management ranks and progress. Organizational climate has important bearing on the level of QWL. This further suggests that organizations can take tactical actions to improve the working climate to achieve the desirable quality of work life and particular desired working behavior and implicitly, the underlying implications of performance. QWL increases when the managers are satisfied with their level of organizational climate being the prime factor, followed by career achievement, career satisfaction and career balance. In this light, there ought to exist a harmony relationship between the organization and the individual so that partnership between the personenvironment needs and values is well-established and favorable. In a positive, participative work climate, the managers have a higher sense of accomplishment and the organizational climate forms a psychological basis in achieving QWL.

The result of this study supports the proposition that the degree of satisfaction in QWL is related to the degree to which the individual believes his or her success criteria have been met, especially if the individual places great importance on these criteria which include organizational climate, pay, respect, personal growth and family life balance. This supports the materialistic work ethic that place strong emphasis on corporate power, income and personal growth as parts of their careers. It can also be concluded from the data, that the individual's family life correlates significantly with his/her level of QWL. This further suggests that a successful family life carries over into one's career and makes one more satisfied with personal achievements.

The fact that is worthy of conclusion is the importance of career achievement in QWL. In the current context, the emphasis is on income, position and personal growth and opportunity in career mobility as potential success indicators. Further, this is related to having a harmonious successful home environment from spousal and family support that is highly valued where career balance is expected to provide some impact as found in this study. It can thus be concluded that the essential predictors of QWL appears to be career related and these career elements are not in isolation but in harmony with the organizational climate. By taking into account the managers' and executives' met expectations of their career development, QWL can be heightened through harmonious organizational climate that serves as a psychological dynamism.

Some suggestions for future research: This study has the potential value for further research. To ensure representativeness, the study should be replicated to cover a bigger sampling frame in other states and the results should be compared to those found in this study. Future research should further explore the perception of career and understand that changes may take place in that perception as life events occur and how social values relate to career elements and family elements if we are to increase our present limited ability to explain individual's QWL. Given the changes experienced by organizations that can include the virtual organizations and telecommuting, one possible insight is to evaluate the extent of QWL and the desirable level in such postmodern climate where flexibility into organizational structures and work schedules are emerging.

\section{REFERENCES}

1. Straw, R.J. and C.C. Heckscher, 1984. QWL: New working relationships in the communication industry. Labor Studies J., 9: 261-74.

2. Cunningham, J.B. and T. Eberle, 1990. A guide to job enrichment and redesign. Personnel, 67: 56-61.

3. Feuer, D., 1989. Quality of work life: a cure for all ills? Training: The Magazine of Human Resources Development, 26: 65-66.

4. Walton, R.E., 1975. Criteria for Quality of Working Life. In Davis, L.E., Cherns, A.B. and Associates (Eds.) The Quality of Working Life, The Free Press, New York, NY, 1: 91-104.

5. Shamir, B. and I. Salomon, 1985. Work-at-home and the quality of working life. Acad. Manag., 10: 455-64.

6. Lewis, S. and C.L. Cooper, 1999. The work-family research agenda in changing contexts. J. Occupat. Health Psychol., 4: 382-393. 
7. Offerman, L.R. and M.K. Gowing, 1990. Organizations of the future: Changes and challenges. Am. Psychologist, 45: 95-108.

8. Ministry of Finance Malaysia, 2003. Economic Report 2003/2004, PNMB, Kuala Lumpur.

9. MIDA Report, 2003. Retrieved June 11, 2003. http://www.mida.org/stats_report.html.

10. Akyüz, Y., 2003. Developing countries and world trade: performance and prospects, UNCTAD, Geneva, Switzerland.

11. Davis, L.E. and A.B. Cherns et al., 1975. The Quality of Working Life. Volume One: Problems, Prospects and the State of the Art. New York: The Free Press.

12. Lawler, E.E.III., 1982. Strategies for improving the quality of work life. Am. Psychologist, 37: 486493.

13. Morrison, R.F. and R.L. Holzbach, 1980. The Career Manager Role. In C.B. Derr (Ed.), Work, Family and the Career. New York: Praeger.

14. Arthur, M.B., D.T. Hall and B.S. Lawrence, 1989. Generating New Directions in Career Theory: The Case for a Transdisciplinary Approach. In M. B. Arthur, D. T. Hall, \& B. S. Lawrence (Eds), Handbook of Career Theory. Cambridge: Cambridge University Press, pp. 7-25.

15. Seashore, S.E., 1975. Defining and Measuring the Quality of Working Life. In Davis L.E. and Cherns, A.B. (Eds.), The Quality of Working Life, The Free Press, New York, NY, pp: 105-18.

16. Loscocco, K.A. and A.R. Roschelle, 1991. Influences on the quality of work and non-work life: two decades in review. J. Vocational Behavior, 39: 182-225.

17. Pelsma, D.M., G.V. Richard, R.G. Harrington and J.M. Burry, 1989. The quality of teacher work life survey: A measure of teacher stress and job satisfaction. Measurement and Evaluation in Counseling and Development, 21: 165-76.

18. Hart, P.M., 1994. Teacher quality of work life: integrating work experiences, psychological distress and morale. J. Occupat. Organ. Psychol., 67: 109-32.

19. Winter, R., T. Taylor and J. Sarros, 2000. Trouble at mill: quality of academic worklife issues within a comprehensive Australian university. Studies in Higher Education, 25: 279-94.

20. Greenhaus, J.H., S. Parasuraman and W.M. Wormley, 1990. Effects of race on organizational experiences, job performance evaluations and career outcomes. Acad. Manag. J., 16: 129-37.

21. Korman, A.K., S.R. Mahler and K.A. Omran, 1983. Work ethics and satisfaction, alienation and other reactions. In Walsh, W.B. and Osipow, S.H. (Eds), Handbook of Vocational Psychology. The Free Press, Hillsdale, New Jersey, 2: 181-206.

22. Shaffer, G.S., 1987. Patterns of work and non-work satisfaction. J. Appl. Psychol., 72: 115-24.
23. Rapoport, R. and R.N. Rapoport, 1980. Balancing Work, Family and Leisure: A Triple Helix Model. In Derr C.B. (Ed.). Work, family and the career, Praeger, New York.

24. Judge, T.A. and R.D. Bretz, 1994. Political influence behavior and career success. J. Manag., 20: 43-65.

25. Cox, C.J. and C.L. Cooper, 1989. The making of the British CEO: Childhood, work experience, personality and management style. Acad. Manag. Executive, 3: 241-45.

26. Cannings, K. and C. Monmarquette, 1991. Managerial momentum: A simultaneous model of the career progress of male and female managers. Industrial and Labor Relations Review, 44: 212-28.

27. Herriot, P., 1992. The Career Management Challenge. Sage, London.

28. Gattiker, U.E. and L. Larwood, 1990. Predictors for career achievement in the corporate hierarchy. Human Relations, 43: 703-26.

29. Carson, K.D., P.P. Carson, J.S. Phillips and C.W. Roe, 1996. A career entrenchment model: Theoretical development and empirical outcomes. J. Career Develop., 22: 273-286.

30. Igbaria, M., 1991. Job performance of MIS professionals: an examination of the antecedents and consequences. J. Engg. Technol. Manag., 8: 141-171.

31. Gaertner, K.N., 1989. Winning and losing: Understanding managers' reactions to strategic change. Human Relations, 42: 527-546.

32. Herriot, P., P. Gibbons, C. Pemberton and P.R. Jackson, 1994. An empirical model of managerial careers in organizations. Br. J. Manag., 5: 113-121.

33. Rice, R.W., S.M. Phillips and D.B. McFarlin, 1990. Multiple discrepancies and pay satisfaction. J. Appl. Psychol., 75: 386-393.

34. Judge, T., D. Cable, J. Boudreau and R. Bretz, 1995. An empirical investigation of the predictors of executive career success. Personnel Psychol., 48: 485-519.

35. Veiga, J., 1983. Mobility influences during managerial career stages. Acad. Manag. J., 26: 6485.

36. Netemeyer, R.G., J.S. Boles and R. McMurrian, 1996. Development and validation of work-family conflict and family-work conflict scales. J. Appl. Psychol., 81: 400-10.

37. Burke, R.J., 1988. Some antecedents and consequences of work-family conflict. J. Social Behavior and Personality, 3: 287-302.

38. Frone, M.R., M. Russell and M.L. Cooper, 1992. Antecedents and outcomes of work-family conflict: Testing a model of the work-family interface. J. Appl. Psychol., 77: 65-78.

39. Pleck, J.H., L.S. Graham and L. Linda, 1980. Conflicts between work and family life. Monthly Labor Review, 103: 29-33. 
40. Greenhaus, J.H. and N.J. Beutell, 1985. Sources of conflict between work and family roles. Acad. Manag. Rev., 10: 76-88.

41. Gutek, B.A., S. Searle and L. Klepa, 1991. Rational versus gender role expectations for workfamily conflict. J. Appl. Psychol., 76: 560-68.

42. Voydanoff, P., 1988. Work role characteristics, family structure demands and work/family conflict. J. Marriage and the Family, 50: 749-61.

43. Higgins, C., L. Duxbury and R.H. Irving, 1992. Work-family conflict in the dual-career family. Organizational Behavior and Human Decision Processes, 51: 51-75.

44. Cascio, W.F., 2005. Managing Human Resources: Productivity, Quality of Work Life, Profits.

45. Nunnally, J.C., 1978. Psychometric Theory. $2^{\text {nd }}$ Edn. McGraw-Hill, New York, NY.

46. Sapsford, R., 1999. Survey research, Sage, Thousand Oaks, CA.

47. Allen, D.R. and T.R. Rao, 2000. Analysis of customer satisfaction data, ASQ Quality Press, Milwaukee, WI.
48. Sekaran, U., 2000. Research Methods for Business: A Skill-Building Approach. $3^{\text {rd }}$ Edn., Wiley, New York.

49. Chatman, J.A., 1989. Improving interactional organizational research: A model of performanceorganization fit. Acad. Manag. Rev., 14: 333-349.

50. Day, D.V. and A.G. Bedeian, 1991. Predicting job performance across organizations: The interaction of work orientation and psychological climate. J. Manag., 17: 589-600.

51. Sommer, S.M., S.H. Bae and F. Luthans, 1995. The structure-climate relationship in Korean organizations. Asia Pacific J. Manag., 12: 23-36.

52. Vallen, G.K., 1993. Organizational climate and burnout. Cornell Hotel and Restaurant Administration Quarterly, 34: 54-9.

53. Lundberg, C.D. and M.F. Peterson, 1994. The meaning of working in the U.S. and Japanese local governments at three different hierarchical levels. Human Relations, 47: 1459-87.

54. England, P. and J. Misumi, 1986. Work centrality in Japan and the United States. J. Cross-Cultural Psychol., 17: 399-416. 